\title{
Correction to: Treatment of Obesity in Young People-a Systematic Review and Meta-analysis
}

\author{
Subothini Sara Selvendran ${ }^{1} \cdot$ Nicholas Charles Penney ${ }^{1} \cdot$ Nikhil Aggarwal $^{1} \cdot$ Ara Warkes Darzi $^{1} \cdot$ Sanjay Purkayastha ${ }^{1,2}$
}

Published online: 7 June 2018

(C) The Author(s) 2018

\section{Correction to: Obesity Surgery \\ https://doi.org/10.1007/s11695-018-3285-x}

In the original article, due to a production error, the text for the "Principle Findings" section was omitted as was the heading for the "Strengths and Limitations" section. The original article has been updated to correct these errors.

The online version of the original article can be found at https://doi.org/ $10.1007 / \mathrm{s} 11695-018-3285-\mathrm{x}$

$\triangle$ Nicholas Charles Penney n.penney@imperial.ac.uk

1 Department of Surgery and Cancer, Imperial College London, London, UK

2 Imperial Weight Centre, St Mary's Hospital, London, UK 